\title{
Okul Yöneticilerinin Kullandıkları Motivasyonel Dil ile Öğretmen Motivasyonu Arasındaki İlişki
}

\section{The Relationship Between Motivational Language Used by School Administrators and Teacher's Motivation}

\author{
Selçuk Demir ${ }^{\text {a,* }}$ \\ ${ }^{a}$ Gaziantep Üniversitesi, Eğitim Bilimleri Enstitüsü, Eğitim Yönetimi, Teftişi, Planlaması ve Ekonomisi Bölümü, 27310, Gaziantep/Türkiye. \\ ORCID: 0000-0003-2904-6443
}

\section{MAKALE BİLGİṠ \\ Makale Geçmişi: \\ Başvuru tarihi: 15 Şubat 2018 \\ Düzeltme tarihi: 17 Şubat 2018 \\ Kabul tarihi: 26 Mart 2018}

\section{Anahtar Kelimeler:}

Motivasyonel Dil

Motivasyon

Okul Yöneticisi

Öğretmen

\section{ARTICLE INFO}

\section{Article history:}

Received 15 February 2018

Received in revised form 17 February 2018

Accepted 26 March 2018

\section{Keywords:}

Motivational Language

Motivation

School Administrator

Teacher
ÖZ

$\mathrm{Bu}$ çalışmanın amacı okul yöneticilerinin kullandıkları motivasyonel dil ile öğretmen motivasyonu arasındaki ilişkiyi belirlemektir. Araştırmada korelasyonel desen kullanılmıştır. Araştırmanın örneklemini, 2016-2017 eğitim-öğretim yılında Hatay il merkezinde yöneticilerinin en az bir y1l görev yaptığ 152 kamu ortaokulundaki öğretmenler oluşturmaktadır. Ölçekler belirlenen okullardaki tüm öğretmenlere verilmiş olup, ölçeklerin 781 tanesi geçerli olduğu tespit edilip analize alınmıştır. Verilerin toplanmasında "Motivasyonel Dil Ölçeği” ve "Öğretmen Motivasyonu Ölçeği" kullanılmıştır. Veriler SPSS programı ile analiz edilmiştir. Regresyon analizi sonuçlarına göre; okul yöneticilerinin kullandıkları motivasyonel dil öğretmenlerin motivasyonunu anlamlı olarak yordamaktadır. Öğretmenlerin motivasyon düzeylerini arttırmak isteyen okul yöneticilerinin motivasyonel dillerini güçlendirme ve geliştirme çalışmalarında fayda görülmektedir.

\section{A B S T R A C T}

In this study, it was aimed to examine the relationship between school managers' motivational language and teacher's motivation. Correlational design was used. The research sample consists of teachers in 52 middle schools whose managers have worked at least a year, in Hatay's city center during 2016-2017 academic year. The surveys were administered to all the teachers working at the selected schools and 781 of the questionnaires were validated and taken into analysis. Data analyses were performed with the program of SPSS. Data were collected by "Motivational Language Scale" and "Teacher Motivation Scale". According to the regression analysis findings, motivational language used by school administrators significiantly predicts teachers' motivation. It may be beneficial for school administrators to invest in developing and strengthening their motivating language, if they want teachers' motivation to enhance.

\section{Giriş}

İnsan sermayesinin etkili bir biçimde yönetilememesi hem örgütlerin hem de çalışanların verimliliği açısından ciddi kayıplara yol açabilir. Bu kayıplar nedeniyle örgütlerde belirlenen hedeflere ulaşılması zorlaşır. Okullarda öğretmenlerin potansiyellerinin ortaya çıkmasına uygun ortam oluşturulmadığında ya da öğretmenler potansiyellerini geliştirmelerine firsat verecek işlere koşulmadıklarında pasif ve isteksiz hale gelirler. İşlerine karşı isteksizlik sergileyen öğretmenlerin ise motivasyon sorunu yaşadıkları belirtilebilir.
İnsan sermayesi örgütlerin sahip olduğu önemli kaynaklardandır (Leal vd., 2015; Longo ve Mura, 2011). Somut varlıkların aksine, soyut bir kavram olan insan sermayesi örgüt yaşamının devam ettirilmesi, entelektüel yenilikler yaratarak rekabet avantajı sağlanması, dolayısıyla örgütün geliştirilmesi açısından oldukça önemli görülmektedir (Huselid, 1995; Mayfield ve Mayfield, 2004; Sun vd., 2016). Sun vd. (2016), insan kaynakları yönetiminde çalışanların liderlik aracılığıyla işlerine nasıl motive olmalarının sağlanacağı hem akademik araştırmacıların hem de uygulayıcıların üzerinde

\footnotetext{
* Sorumlu yazar/Corresponding author.

e-posta: selcuk_demirs@hotmail.com
} 
yoğunlaştıkları ortak konulardan birisi olduğunu belirtir. Liderin astlarıyla etkileşimlerinde lider dilinin onları harekete geçirici bir güç olarak önemli imkânlar sunduğu önceki çalışmalarda görülmektedir (Mayfield ve Mayfield, 2006). Çalışanların güdülenmesi ve işyerindeki performanslarının artması noktasında liderin motive edici bir dil kullanımının önemli olduğu bazı araştırmalarca da kanıtlanmıştır (Banks, 2014; Brannon, 2011; GutierrezWirsching vd., 2015; Larsson vd., 2007; Majors, 2008; Mayfield ve Mayfield, 2007; Mayfield vd, 1998; Mayfield ve Mayfield, 2012; Mert, 2011; Mert vd., 2011; Sullivan, 1988; Sun vd., 2016). Okullarının lideri konumunda olan yöneticilerin motivasyonel dil kullanarak öğretmenlerin motivasyonlarını arttırmalarının mümkün olduğu düşünülmektedir.

\section{Kavramsal Çerçeve}

\subsection{Motivasyonel Dil}

Sullivan (1988) çalışanların olumlu çıktılar elde etmelerinde başarılı yöneticilerin iletişimlerine odaklanma yoluyla etkili iletişim taktiklerinin sunulmasına ilişkin liderlerin kullanacağı anlaşılır bir model öneren Motivasyonel Dil Teorisini geliştirmiştir. $\mathrm{Bu}$ modelin birkaç varsayımı bulunmaktadır. Birinci olarak motivasyonel dil sözel iletişimin en anlamlı ve en küçük birimleri olan üç dil ediminin birleşimini temsil eder. Bu dil edimleri yönlendirici dil, empatik dil ve anlam oluşturucu dil edimi olmak üzere üç unsurdan oluşur (Mayfield vd., 1995, 1998; Sullivan, 1988). Bu üç unsur örgütsel yapılara şu şekilde uyarlanır:

(i) Yönlendirici dil liderin belirsizliği azaltma yoluyla çalışanlara sorumluluklar, ödüller ve hedefler konusunda açıklamalar yaptığında kullanılmış olmaktadir.

(ii) Empatik dil çalışanların başarılarından övgü ile söz edilmesi, iş ve kişisel sorunlarına özel ilgi gösterilmesi gibi liderin şefkat ve değer vermesi durumlarında oluşur.

(iii) Anlam oluşturucu dil liderler her örgütün kendine özgü kültürünü, yapısını ve değerlerini çalışanlara aktardığında ortaya çıkar.

Motivasyonel dil teorisinin sunduğu modelin ikinci varsayımı, liderlerin davranışlarının söylemlerini takip etmesidir. Üçüncüsü ise, liderin uygun zamanlarda bu üç dil ediminden faydalanmasının onları en iyi sonuca götüreceğini varsaymasıdır (Gutierrez-Wirsching vd., 2015; Mayfield vd., 1995; Sullivan, 1988).

\subsection{Motivasyon}

Örgütsel davranış alanında incelenen önemli kavramlardan biri olan (Robbins ve Judge, 2012) motivasyon kavramı güdüleme, yöneltme, isteklendirme ve teşvik etme anlamlarına gelmektedir (Özkalp ve Kırel, 2010). Motivasyon insan davranışını belirleyen ve yönelten bir enerjidir. Tanımda motivasyonun iki önemli özelliği belirtilmektedir. Birincisi bireyleri belirli bir yönde davranış göstermeye yönelten enerji gücü olması, ikincisi ise hedeflere yöneltmedeki etkisidir (Şimşek vd., 2011). Öğretmenlerin öncelikle işlerini istekle yapmaları, diğer bir ifadeyle işlerine motive olmaları öğrencilerin motivasyonlarını ve dolayısıyla öğrenmelerini sağlama açısından önemli görülmektedir. Nitekim Viau (2015), öğretmenlerin alanlarında uzman ve öğretim için motive olmalarının öğrencilerin öğrenmeye karşı motivasyonlarının geliştirilmesi ve canlandırılması yönüyle önemli olduğunu belirtir. Ayrıca öğretmenlerin işlerine güdülenmeleri sağlanmadan öğrencilerinin güdülenmelerinin beklenemeyeceğini ileri sürer.

\subsection{Motivasyonel Dil ile Motivasyon arasındaki İlişki}

Sullivan (1988), liderin astları ile etkileşimlerinde kullandığı dilin, yönlendirici olmasının yanında, empati kurma ve anlam oluşturma edimlerini de içermesi gerektiğini, aksi takdirde başarılı bir etkileşimin gerçekleşmeyeceğini belirtir. Liderin astlarıyla etkileşiminin kalitesinin bu üç söz edimini yerinde ve güçlü kullanma başarısıyla doğru orantılı olduğu araştırmalarda vurgulanmaktadır (Mayfield vd., 1998; Sullivan, 1988). Liderin üç dil edimini birlikte kullanma yeterliğine sahip olması astları üzerinde motive edici bir güç oluşturur (Sullivan, 1988; Mayfield vd., 1995, 1998). Lider yönlendirici dil ile çalışanlarını işle ve örgütle ilgili bilgilendirir ve kurumdaki belirsizlikleri azaltır. Lider empatik dil kullanarak çalışanlarını elde ettikleri başarılarından dolayı takdir eder ve onları diğerlerinin yanında över. Anlam oluşturucu dil kullanarak ise örgütün kurallar ve değerlerinin çalışanlar tarafından özümsenmesini sağlar. Kullanılan üç dil ediminin başarılı birleşimi ile astlar örgütlerine duygusal olarak bağlı ve örgütü için elinden gelenin en iyisini coşku içinde yapmaya hazır olurlar.

Liderler sahip oldukları iletişim becerileri ile lider etkililiklerini arttırır ve astların örgütler için anahtar rolünde oldukları kabul edilen (iş doyumu, motivasyon vb.) tutumlarını olumlu olarak etkiler (Mayfield ve Mayfield, 2006; Simmons ve Sharbrough, 2013). Güdülenme, etkinlik ve verimlilik oluşturma yöneticilerin çalışanları ile kuracakları etkili iletişimle mümkün olabileceği görülmektedir. Şenturan (2014), insanları motive etmenin önemli bir aracının kurulacak olan sağlıklı iletişim olduğunu belirtir. Simmons ve Sharbrough (2013) ise liderin iletişiminde belirsizlikleri azaltıcı ve empatik yaklaşımının önemli olduğunu vurgulamaktadır. Eğitim örgütlerinde öğretmenlerin belirli bir davranışın belirli bir amaçla gerçekleşeceğini bilmeleri, buna inanmaları ve sonuca yükledikleri anlamların değerli hale gelmesi yöneticisinin iletişim becerileriyle gerçekleşebilir. $\mathrm{Bu}$ bağlamda düşünüldüğünde yöneticilerin kullandıkları dil öğretmenlerin faaliyetlerinin içsel olarak eş güdümlenmesinde önemlidir.

\subsection{Araştırmanın Amacı}

Örgütsel ve bireysel anahtar değişkenler üzerinde olumlu etkisi olduğu bilinen motivasyonel dil kavramının uluslararası alanda artan önemine rağmen, ulusal alan yazında bu konuya yeterli miktarda odaklanılmadığı görülmektedir. $\mathrm{Bu}$ çalışmanın ulusal alan yazında da okul yöneticisinin motive edici diline yoğunlaşılmasına katkı sunacağı düşünülmektedir. Böylelikle motivasyonel dilin daha iyi anlaşılması ve uygulanabilmesine ilişkin stratejik iletişim taktikleri sunması ve var olan bilgileri genişletmesi bakımından eğitim örgütleri açısından olduğu gibi diğer örgütler açısından da bu çalışma önemli görülmektedir. 
Dolayısıyla bu çalışmanın amacı okul yöneticilerinin kullandıkları motivasyonel dil ile öğretmen motivasyonu arasındaki ilişkiyi belirlemektir.

\section{Yöntem}

\subsection{Araștırmanın Desenlenmesi ve Uygulanması}

$\mathrm{Bu}$ araştırmada birden fazla değişken arasındaki ilişkilerin uygulanan ölçekler aracılığıyla araştırıldığı korelasyonel desen kullanılmıştır. Korelasyonel araştırma, bir grup içindeki değişkenler arasındaki ilişkiyi ve sıklıkla değişkenler arasında neden-sonuç olasılığına ilişkin fikir veren çalışmaları içerir (Büyüköztürk vd., 2012; Karasar, 2012). Bu çalışmada da okul yöneticilerinin kullandıkları motivasyonel dilin öğretmen motivasyonu ile ilişkisi ve öğretmen motivasyonunun yordanma gücü ölçekler aracılığıyla tespit edilmeye çalışılmıştır.

\subsection{Evren ve Örneklem}

Araştırmanın çalışma evreni 2016-2017 eğitim-öğretim y1lında Hatay il merkezindeki kamu ortaokullarında görev yapan 1547 öğretmenden oluşmaktadır. Araştırma kapsamında incelenecek değişkenlerin okul müdürünün bulunduğu kurumda belli bir süre görev yapmasından etkileneceği düşünülerek 21 kamu ortaokulunun müdürünün bulunduğu kurumda bir yıldan az süre ile çalışmaları nedeniyle araştırmanın çalışma evrenine dâhil edilmemişlerdir. Diğer bir anlatımla çalışma evreninden örneklem dişı tutma ilkesi olarak müdürün bir yıldan az görev yaptığı okullar hariç tutulmuştur. Bu kapsamda çalışma evreninde yer alan 73 ortaokulun 52 tanesi örnekleme dâhil edilmiş olup, 21 tanesi örneklem dişı tutulmuştur. $\mathrm{Bu}$ doğrultuda araştırmanın çalışma evreni Hatay il merkezinde (Antakya) yer alan 52 kamu ortaokulundaki 1153 öğretmenden oluşmaktadır.

Bir araştırmanın örnekleminin belirlenmesi sırasında bütün yöntemler belirli bir oranda örnekleme hatasının etkisinde kalmaktadır. $\mathrm{Bu}$ durum genelde örnekleme yöntemi kullanılarak gerçekleştirilen araştırmalarda yöntemin yapısından ya da evrene gerçek manada gidilemediği için alınan kesitten yapılan yaklaşık ölçümlerden kaynaklanır (Aziz, 2015). Bu nedenle bu araştırmada ayrı bir örnekleme yoluna gidilmemiş, evrenin tamamına ulaşılmaya çalışılmıştır. Bu şekilde evrene gerçek manada gidilip ölçmede oluşabilecek hatayı en aza indirgemek amaçlanmıştır. Dolayısıyla bu okullardaki öğretmenlerin tamamına bilgi verilip ölçekler ulaştırılmıştır. Gönüllülük esas alınarak bu ortaokullarda çalışan 781 öğretmen araştırmaya katılmıştır.

Örnekleme katılan öğretmenlerin $(\mathrm{n}=781) \% 49.6$ 's1 erkek $(n=387), \% 50.4$ 'ü kadınlardan $(n=394)$ oluşmaktadır. Örnekleme katılan öğretmenlerin $(n=781)$ \%73'ü evli $(n=570)$ iken \%27'si bekâr öğretmenlerden $(n=211)$ oluşmaktadır. Örneklemi oluşturan öğretmenlerin çoğunluğu evlidir. Örnekleme katılan öğretmenlerden $(\mathrm{n}=781)$ k1demlerinin en çok frekans gösterdiği aralık \%28,7 ile 1-5 yıl aralığındaki öğretmenler $(\mathrm{n}=224)$ oluşturmaktadır. En az frekans gösterilen aralık ise $\% 4,5$ ile 26 yıl ve üzeri aralığındaki öğretmenler $(n=35)$ oluşturmaktadır. Tablodan anlaşılacağı üzere örneklemi oluşturan öğretmenlerin çoğu bayan, evli ve öğretmenlik mesleğinde 10 yıl ve altında çalışan öğretmenlerdir.

\subsection{Veri Toplama Araçları}

Araştırma değişkenlerinin ölçümünde motivasyonel dil ve öğretmen motivasyonu ölçekleri kullanılmıştır. Ölçekler beşli likert tipinde olup seçenekleri, "1= Hiç katılmıyorum"; " $2=$ Kat1lmiyorum"; " $3=$ Kismen kat1liyorum"; " $4=$ Katılıyorum"; ve "5= Tamamen katıliyorum" şeklinde değişmektedir. Katılımcılardan kendi algılarına en uygun yanıtı seçmeleri istenmiştir.

$\mathrm{Bu}$ araştırmada öğretmen algılarına göre okul müdürlerinin kullandıkları motivasyonel dilin ölçümü için kullanılan ölçek Mayfield vd. (1995) tarafından geliştirilmiş ve Özen (2013) tarafindan Türkçe' ye uyarlanmıştır. Orijinal formu 24 madde ve üç boyuttan oluşmaktadır. Yönlendirici dil boyutunun açıkladığı varyans yüzdesi 27.70 , cesaret verici dil (empatik dil) boyutunun açıkladığı varyans yüzdesi 24.48, aitlik yaratıc1 dil (anlam oluşturucu dil) boyutu tarafından açıklanan varyans yüzdesi 17.50 ve bu üç boyutun açıkladığı toplam varyans yüzdesi 69.68 olarak bulunmuştur. Cronbach Alfa iç tutarlılık katsayısı yönlendirici dil alt boyutunda 0.94 , cesaret verici dil alt boyutunda 0.93 , aitlik yaratıcı dil alt boyutunda ise 0.88 ve ölçeğin tamamında ise 0.97 olarak hesaplanmıştır.

Öğretmen motivasyonunu ölçmek için kullanılan ölçek ise Gagne vd. (2010) tarafından geliştirilmiş ve Akbolat ve Işı1k (2012) tarafindan Türkçe' ye uyarlanmıştır. Orijinal formu 12 maddeden ve dört boyuttan oluşmaktadır. Orijinal formu dört boyutlu olan ölçeğin açıkladığı varyans yüzdesi içsel motivasyon alt ölçeğinde 51.050, özdeşleşmiş düzenleme 12.02, içe yansitılmış düzenleme alt ölçeğinde 8.77 , dişsal düzenleme 5.81 ve bu dört boyutun açıkladığı toplam varyans yüzdesi 77.65 bulunmuştur. Cronbach Alfa iç tutarlılık katsayısı içsel motivasyon alt boyutunda 0.88 , özdeşleşmiş düzenleme alt boyutunda 0.91 , içe yansitılmış düzenleme alt boyutunda 0.78, dişsal düzenleme alt boyutunda 0.68 ve ölçeğin tamamında 0.90 olarak hesaplanmıştır.

\subsection{Verilerin Analizi}

Değişkenlerle ilgili betimsel analizler yapılmış ve değişkenler arasındaki ilişkiler korelasyon analizi ile tespit edilmiştir. Ardından kısmi doğrusal regresyon analizi ile öğretmen motivasyonunun okul yöneticilerinin kullandıkları motivasyonel dil tarafindan yordanma gücü belirlenmiştir.

\section{Bulgular}

\subsection{Değişkenlerle İlgili Betimsel Analizler ve Korelasyon Matrisi}

Öğretmenlerin, araştırma kapsamında uygulanan ölçme araçlarındaki maddelere katılım düzeylerini gösteren aritmetik ortalama, standart sapma ve standart hata değerleri ile değişkenler arası ilişkilerin düzeyi ve yönünün belirtildiği korelasyon değerleri birlikte Tablo 1 'de verilmektedir.

Tablo 1. Motivasyonel Dil İle Öz Yeterlik Ortalama, Standart Sapma, Standart Hata Sonuçları ve Korelasyon Değerleri 


\begin{tabular}{lccccc}
\hline Değişkenler & $\overline{\mathrm{X}}$ & ss & Std. Hata & 1 & 2 \\
\hline 1. Motivasyonel Dil & 3.83 & 0.028 & 0.79 & 1 & \\
2. Motivasyon & 3.76 & 0.023 & 0.67 & 0.52 & 1 \\
\hline
\end{tabular}

Tablo 1'e göre, öğretmenlerin okul yöneticilerinin kullandıkları motivasyonel dil $(\overline{\mathrm{X}}=3.83)$ ve öğretmen motivasyonları ( $\bar{X}=3.76$ ) "Katıllyorum (4)" düzeyindedir. Dolayısıyla okul yöneticisinin kullandığı motivasyonel dile ve motivasyona ilişkin öğretmen algıları kısmen yüksek düzeydedir. Öğretmen algılarına göre okul yöneticilerinin kullandıkları motivasyonel dil puanları ile öğretmen motivasyonu puanlarının birbirine çok yakın değerlerde olduğu görülmektedir. Korelasyon matrisindeki ilişkilere bakıldığında, okul yöneticilerinin kullandıkları motivasyonel dile ilişkin algılar motivasyon algıları ile pozitif korelasyon içindedir $(\mathrm{r}=.52, \mathrm{p}<.001)$.

\subsection{Okul Yöneticisinin Kullandığı Motivasyonel Dilin Öğretmen Motivasyonunu Yordamas1}

Okul yöneticisinin kullandığı motivasyonel dilin öğretmen motivasyonunu yordamasına ilişkin regresyon analizi sonuçları Tablo 2'de verilmiştir.

Tablo 2. Okul Yöneticisinin Kullandığ 1 Motivasyonel Dilin Öğretmen Motivasyonunu Yordamasına İlişkin Regresyon Analizi Sonuçları

\begin{tabular}{|c|c|c|c|c|c|c|}
\hline Model & Yordayıcı değişkenler & B & Std. Hata & $\beta$ & $\mathrm{t}$ & $\mathrm{p}$ \\
\hline \multirow{4}{*}{ 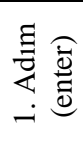 } & Sabit & 3.73 & .10 & \multicolumn{3}{|c|}{$37.46 .00^{* * * *}$} \\
\hline & Cinsiyet (dummy) & -.06 & .04 & -.04 & -1.29 & .19 \\
\hline & Medeni durum & .03 & .05 & .02 & .51 & .60 \\
\hline & Kidem & .00 & .00 & .02 & .59 & .54 \\
\hline \multirow{5}{*}{ 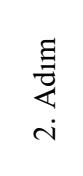 } & Sabit & 2.06 & .13 & \multicolumn{3}{|c|}{$15.82 .00 * * *$} \\
\hline & Cinsiye & -.04 & .04 & -.03 & -1.09 & .27 \\
\hline & Medeni Durum & .01 & .04 & .00 & .22 & .82 \\
\hline & Kider & .00 & .00 & .02 & .71 & .47 \\
\hline & Motivasyonel Dil & .44 & .02 & .52 & \multicolumn{2}{|c|}{$17.04 .00 * * *$} \\
\hline
\end{tabular}

Yapılan regresyon analizinde, demografik değişkenler 1. adımda kontrol edilerek 2. adımda okul yöneticilerinin kullandıkları motivasyonel dilin, öğretmenlerin motivasyonlarını anlamlı bir şekilde yordadığı görülmektedir $(\beta=0.52 * * *, p=0.00)$. 1 birimlik motivasyonel dil artışı 0.52 birimlik motivasyon artışını sağlamaktadır. Öğretmenin motivasyon düzeyi üzerindeki varyansın \%27,4'ü okul yöneticilerinin kullandıkları motivasyonel dil tarafindan açıklanmaktadır $\left(\Delta \mathrm{R}^{2}=.274 ; \mathrm{p}=0.00\right) . \quad \mathrm{Bu}$ doğrultuda okul yöneticilerinin kullandıkları motivasyonel dil arttıkça öğretmenlerin motivasyon düzeyleri artmaktadır.

\section{Sonuç ve Değerlendirme}

$\mathrm{Bu}$ araştırmada betimsel analiz sonuçlarına göre okul yöneticilerinin kullandığı motivasyonel dile ve öğretmen motivasyonuna ilişkin öğretmen algıları kısmen yüksek düzeyde olduğu tespit edilmiştir. Korelasyon matrisindeki ilişkiler incelendiğinde, okul yöneticilerinin kullandıkları motivasyonel dile ilişkin algılar motivasyon algıları ile pozitif korelasyon içinde olduğu görülmüştür. Yapılan regresyon analizinde ise, okul yöneticilerinin kullandıkları motivasyonel dilin, öğretmenlerin motivasyonlarını anlamlı bir şekilde yordadığı görülmektedir.
Murray (2015), bazı liderlerin yeni liderde $\operatorname{aradığ~}$ özelliğin sözel iletişim becerilerini kullanarak çalışanların işlerine motive olmalarını, hatta işyerinde sorun oluşsa bile sözlü iletişim yoluyla çalışanları tekrar motive edebilme olduğunu vurgular. Benzer şekilde McMeans (2001), başarılı liderlerin çalışanlarını motive etmede ve değişen durumlara uyum sağlamada sözel iletişimi bir araç olarak kullandıklarını belirtir. İlgili alan yazın incelendiğinde liderin kullandığı motivasyonel dilin çalışanın motivasyon düzeyini olumlu olarak yordadığı araştırma bulgusunu destekleyen çalışmalar bulunmaktadır (Banks, 2014; Brannon, 2011; Larsson vd., 2007; Mayfield ve Mayfield, 2007; Mayfield vd., 1998; Sullivan, 1988).

Motivasyonla yakın ilişkili olduğu bilinen performans kavram1 (Gagne ve Deci, 2005; Güney, 2012; Ryan ve Deci, 2000; Saygın ve Saygın, 2016; Mert, 2011) ile motivasyonel dilin yönlendirici dil ve empatik dil boyutları arasında anlamlı güçlü bir ilişki gözlenirken, anlam oluşturucu dil boyutu ile görev performansı arasında anlamlı bir ilişki bulunamamıştır (Mayfield ve Mayfield, 2006; Mert vd., 2011). Ayrıca yöneticinin kullandığı motivasyonel dilin, görev performansı üzerinde etkili olduğu bazı araştırmacılar tarafindan bulunmuştur (Gutierrez-Wirsching vd., 2015; Mayfield vd., 1998; Mayfield ve Mayfield, 2006; Mert, 2011; Mert vd., 2011). Nitekim motivasyonun hem uygulamada hem de araştırmalarda kilit rolünde bir performans faktörü olduğu bilinmektedir (Goleman vd., 2012; Huselid, 1995; Kurt, 2005; Pfeffer, 1994; Robbins ve Judge, 2012). Dolayısıyla bu bilgiler 1şı̆̆ında da motivasyonel dil ile motivasyon kavramlarının ilişkili olduğu görülmektedir.

Motivasyonel Dil Teorisi, üç dil söyleminin birlikte kullanılmasıyla çalışanları olumlu manada etkilemede daha başarılı sonuç vermektedir (Latifoğlu, 2015; Mayfield vd., 1995, 1998; Mayfield ve Mayfield, 2007, 2009; Mert, 2011; Sullivan, 1988). Empatik dil, başarıların takdir edilmesi, güven duyulduğunun belirtmesi, sorunlarıyla ilgilenmesi ve böylelikle çalışanların kendilerini değerli hissetmeleri amacıyla kullanılır. $\mathrm{Bu}$ dil ediminin kullanımıyla çalışanlarda işlerine dair olumlu düşüncelerin gelişimi desteklenebilir (Mert, 2011). Bu itibarla yöneticinin empatik dil kullanması çalışanların tatmin düzeyini arttıracağı ve böylelikle çalışanların motivasyonları üzerinde olumlu etki yaratabileceği düşünülmektedir. Kurt (2005) elde edilen başarı karşılığında yöneticilerinden aldıkları övgü dolu sözlerin çalışanların kendine güveninin artmasını destekleyerek motive olmalarını sağladığını ileri sürmektedir.

Yöneticiler kullandıkları motivasyonel dil ile çalışanlarını psikolojik olarak etkiler (Gutierrez-Wirsching vd., 2015). Liderin iletişimi hoşgörü içerdiğinde ve astını görevlerini yerine getirme konusunda yetkilendirdiğinde, astı bunun karşılığında diğerlerinden daha fazla sorumluluk almaya istekli olur ve enerjisini görevini başarılı bir şekilde yapmaya harcar (Laundry ve Vandenberghe, 2009). Anlayışlı ve güven duyan bir dil kullanan lider, çalışanın inisiyatif almasını olanaklı kılar. Bu olumlu hislerin bir sonucu olarak da çalışan işini yapmaya daha çok istek duymaktadır (Murray, 2015).

$\mathrm{Bu}$ çalışma ile motivasyonel dil ve öğretmen motivasyonu değişkenleri arasındaki ilişkiye dair kavramsal çerçeve 
sunulmuştur. Motivasyonel dil kurum yöneticilerinin stratejik iletişimin kolay uygulanabilir bir modelini öneren Motivasyonel Dil Teorisinden daha fazla yararlanabilmelerine imkân sağlamaktadır. $\mathrm{Bu}$ çalışmanın sonuçlarına göre motivasyonel dil teorisinin lider iletişimi ile motivasyon arasında köprü vazifesi gördüğü varsayımı doğrulanmıştır. Öğretmenlerin motivasyon düzeylerini arttırmak isteyen okul yöneticilerinin motivasyonel dillerini güçlendirme ve geliştirme çalışmalarında fayda görülmektedir

$\mathrm{Bu}$ araştırmanın bazı sınırlılıkları bulunmaktadır. Örneklem Hatay il merkezindeki yöneticisinin en az bir yıl süreyle görev yaptığı ortaokullardaki öğretmenlerle sınırlıdır. Diğer bir sinırlılığı ise, değişkenler arasında neden-sonuç ilişkilerine dair güçlü fikirler verilmiş, ama belirlenen ilişkilerin nedenlerinin derinlemesine incelenerek tespiti yapılamamıştır.

\section{Kaynakça}

Akbolat, M., \& Işık, O. (2012). Sağlık çalışanlarının duygusal zekâ düzeylerinin motivasyonlarına etkisi. Dumlupınar Üniversitesi Sosyal Bilimler Dergisi, 32(1), 109-124.

Aziz, A. (2015). Sosyal bilimlerde araştırma yöntemleri ve teknikleri. Ankara: Nobel yayınları.

Banks, T. (2014). The effects of leader speech and leader motivating language on employee self-esteem, Unpublished Doctorate Thesis, School of Business \& Leadership, Regent University, USA.

Brannon, K.L. (2011). The effects of leader communication medium and motivating language on perceived leader effectiveness, Doctorate Thesis. Arizona, USA: Northcentral University.

Büyüköztürk, Ş., Çakmak, E. K., Akgün, Ö. E., Karadeniz, Ş., \& Demirel, F. (2012). Bilimsel araştırma yöntemleri. Ankara: Pegem Akademi Yayıncılık.

Field, A. (2009). Discovering statistics using SPSS. Dubai: Oriental Press.

Gagné, M., \& Deci, E. L. (2005). Self-Determination theory and work motivation. Journal of Organizational Behavior, 26(4), 331-362.

Gagné, M., Forest, J., Gilbert, M., Aubé, C., Morin, E., \& Angela, M. (2010). The motivation at work scale: Validation evidence in two languages. Educational and Psychological Measurement, 70(4), 628-646.

Goleman, D., Boyatzis, R., \& McKee, A. (2012). Yeni liderler. (Çev. Filiz Nayır \& Osman Deniztekin). İstanbul: Varlık yayınları.

Gutierrez-Wirsching, S., Mayfield, J., Mayfield, M., \& Wang, W. (2015). Motivating language as a mediator between servant leadership and employee outcomes. Management Research Review, 38(12), 1234-1250.

Güney, S. (2012). Örgütsel davranış. Ankara: Nobel yayınları.

Huselid, M. (1995). The impact of human resource management practices on turnover, productivity, and corporate financial performance. Academy of Management Journal, 38(3), 635-672.

Karasar, N. (2012). Bilimsel araştırma yöntemi. Ankara: Nobel yayın Dağıtım.

Kurt, T. (2005). Herzberg'in çift faktörlü güdüleme kuramının öğretmenlerin motivasyonu açısından çözümlenmesi. Gazi Ĕ̈itim Fakültesi Dergisi, 25(1), 285-299.

Larsson, R., Brousseau, K. R., Kling, K., \& Sweet, P. L. (2007). Building motivational capital through career concept and culture fit. Career Development International, 12(4), 361-381.

Latifoğlu, N. (2015). Motivasyonel dil kullanımının örgütsel bağlılık üzerindeki etkisi: Çaykur'da bir uygulama. Yüksek Lisans Tezi. Rize: Recep Tayyip Erdoğan Üniversitesi.

Landry, G., \& Vandenberghe, C. (2009). Role of commitment to the supervisor, leader-member exchange, and supervisor based self-esteem in employeesupervisor conflicts. The Journal of Social Psychology, 148 (2), 5-27.

Leal, C., Marques, C., Marques, C., \& Brago-Filho, E. (2015). Internal communication, intellectual capital and job satisfaction: A structural model applied to a credit union. European Conference on Intellectual Capital, 199-207.

Longo, M., \& Mura, M. (2011). The effect of intellectual capital on employees' satisfaction and retention. Information \& Management, 48 (7), 278-287. http://dx.doi.org/10.1016/j.im.2011.06.005.

Majors, J.M. (2008). Motivating language: creating a culture of job satisfaction and performance. Master Thesis. USA: the University of South Alabama.

Mayfield, J., \& Mayfield, M. (2004). The effects of leader communication on worker innovation. American Business Review, 22(2), 45-51.

Mayfield, J., \& Mayfield, M. (2006). The benefits of leader communication on part-time worker outcomes: A comparison between part-time and full-time employees using motivating language. Journal of Business Strategies, 23(2), 131-153.

Mayfield, J., \& Mayfield, M. (2007). The effects of leader communication on a worker's intent to stay: An investigation using structural equation modeling. Human Performance, 20(2), 85-102, http://dx.doi.org/10.1080/08959280701332018.

Mayfield, M., \& Mayfield, J. (2009). The role of leaderfollower relationships in leader communication: A test using the LMX and motivating language models. The Journal of Business Inquiry, 8(1), 65-82.

Mayfield, J., \& Mayfield, M. (2012). The relationship between leader motivating language and self-efficacy: A partial least squares model analysis. Journal of Business Communication, 49(4), 357-376. 
Mayfield, J., Mayfield, M. \& Kopf, J. (1995). Motivational language: Exploring theory with scale development. The Journal of Business Communication, 32 (4), 329-344.

Mayfield, J., Mayfield, M., \& Kopf, J. (1998). The effects of leader motivating language on subordinate performance and satisfaction. Human Resource Management, 37(3-4), 235-248.

McMeans, J. B. (2001). Leader motivating language within an organizational context. Unpublished Doctorate Thesis, Educational Leadership, University of Hartford, USA.

Mert, İ. S. (2011). Yöneticilerin kullandıkları motivasyonel dil ve performans üzerindeki etkisi. Balıkesir Üniversitesi Sosyal Bilimler Enstitüsü Dergisi, 14 (26), 197-214.

Mert, İ.S., Keskin, N., \& Baş, T. (2011). Motivasyonel dil (MD) teorisi ve ölçme aracının Türkçe' de geçerlik ve güvenilirlik analizi. Doğuş Üniversitesi Dergisi, 12 (2), 243-255.

Murray, K. (2015). Liderk dili. (çev. Ümit Şensoy), İstanbul: Türkiye İş Bankası Kültür Yayınları.

Özen, H. (2013). Okul müdürlerine yönelik motivasyonel dil ölçeği: Türk kültürüne uyarlama, dil geçerliği ve faktör yapısının incelenmesi. Eğitim Bilimleri Araştırmaları Dergisi, 3(1), 87-103.

Özkalp, E., \& Kırel, Ç. (2010). Örgütsel davranış. Bursa: Ekin Basım Yayın Dağıtım.

Pfeffer, J. (1994). Competitive advantage through people. Boston, M.A.: Harvard Business School Press.

Robbins, S. P., \& Judge, T. A. (2012). Örgütsel davranış. (çev. ed. İ. Erdem). İstanbul: Nobel Akademik Yayınc1lik.

Ryan, R. M., \& Deci, E. L. (2000). Self-determination theory and the facilitation of intrinsic motivation, social development, and well-being. The American Psychologist, 55(1), 68-78.

Saygın, O., \& Saygın, E. (2016). A' dan Z' ye liderlik. İstanbul: Karma Kitaplar Yayıncılık.

Simmons, S. A., \& Sharbrough, W. C. (2013). An analysis of leader and subordinate perception of motivating language. Journal of Leadership, Accountability and Ethics, 10(3), 11-27.

Sullivan, J. J. (1988). Three roles of language in motivating theory. The Academy of Management Review, 13(1), 104115.

Sun, P. C., Pan, F. T., \& Ho, C. W. (2016). Does motivating language matter in leader-subordinate communication?. Chinese Journal of Communication, 9(3), 264-282. http://dx.doi.org/10.1080/17544750.2016.1206029

Şenturan, Ş. (2014). Örnek olaylarla örgütsel davranış. İstanbul: Beta Yayıncılık.

Şimşek, Ş., Akgemci, T., \& Çelik, A. (2011). Davranış bilimlerine giriş ve örgütlerde davranış. Ankara: Gazi Kitabevi.
Viau, R. (2015). Okulda motivasyon, okulda güdüleme ve güdülenmeyi ögrenme. (Çev. Yusuf Budak). Ankara: Anı Yayınc1lık. 